effects, particularly in older women. In this re spect, however, two points have to be considered.

A recent investigation in a limited number of patients seems to support the view of the authors, but another study in 171 patients shows that the prevalence of vertebral deformities on radiographs is no greater than that found in a sample of age matched normal subjects. ${ }^{3}$ In that study no in creased trabecular bone loss was detected in iliac bone biopsy specimens. In patients with mild primary hyperparathyroidism bone mineral content did not decline with time in accordance with the hypothesis that this may be a disease of set point abnormality. ${ }^{4}$

On the basis of these conflicting results we suggest that, until controlled prospective clinical studies are performed, bone loss should not be considered as the criterion of choice to advise immediate surgery in patients with mild asymptomatic primary hyperparathyroidism.

SALVATORE Minisola

VINCENZO CARNEVAL

Fiavio Big

Università di Roma "La Sapienza,"

Policlinico Umberto I,

00161 Rome, Italy

1 Palmer M, Adami HO, Bergstrom R, Akerstrom G, Ljunghall S Mortality after surgery for primary hyperparathyroidism: follow-up of 441 patients operated on from 1956 to 1979. Surgery 1987;102:1-7.

2 Kochersberger G, Buckley NJ, Leight GS, et al. What is the clinical significance of bone loss in primary hyperparathyroidism? Arch Intern Med 1987;147:1951-3.

3 Wilson R, Rao SD, Kleerekoper M, Parfitt AM. Is asymptomatic primary hyperparathyroidism (PHPT) a risk factor for vertebral compression fracture (VCF)? foumal of Bome and Mineral Research 1987;2:109.

4 Wilson R, Rao DS, Parfitt AM, Pumo B, Frame B, Kleerekoper M. Lack of cos, Parfin AM, Pumo B, Fra B, Kleerekoper $M$. Lack of continued effect of parathyroid hormone on bone mineral content in patients with untreated asymptomatic primary hyperparathyrin T Meunier PJ, eds. Calcium regulation and bone metabolism: basic
and clinical aspects. New York: Excerpta Medica, 1987:560.

\section{Deaths from injury}

SIR,--Mr I D Anderson and others (7 May, p 1305) advise consideration of the place of trauma centres in the management of severe injury.

The deficiencies in trauma care in Britain arise from lack of organisation of trauma services Certain concepts will undoubtedly change in time, but a sound organisation must be based on three immutable principles - total care of the patient by the same team, continuity of care by that team, and participation of the experienced trauma surgeon at an early stage.

Deaths after injury occur primarily because of missed diagnosis, failure to control haemorrhage or hypoxia, and inadequate, delayed, or nonexistent surgical intervention. The development of trauma centres seems ideal provided that the following errors are not repeated.

Doctors and administrators of every teaching and district general hospital must be aware that no all can or should have a specialised trauma unit. Such designation should not be made, as was done in the past, by simply changing the name of any department. A multidisciplinary medical committee approach causes only fragmentation in the management and is inefficient and costly. People will continue to die unnecessarily as long as all hospitals are allowed to admit trauma patients. Many are not treating major injuries adequately. Trauma is a surgical specialty and demands the constant sensitive judgment of a surgeon and an anaesthetist who oversee the continuing care of the patient. Care of the trauma victim in many hospitals in the United Kingdom, however, is delegated to doctors who have no, or very little, experience. There is no career structure in the surgery of trauma, and the care of severely injured patients is entrusted to many disciplines without any formal training or skill.

We believe in the concept of trauma centres but we must start training surgeons in the surgery of trauma as a distinct specialty; otherwise the establishment of trauma centres is doomed to failure.

E K ALPAR

R F EvANS

Birmingham Accident Hospital,

$M$ W GHORIS

Birmingham B15 1NA

\section{BMA council election results}

SIR,-I have often argued-unsuccessfully-that the electoral system should be improved. But before we take seriously the concern of the Central Committee for Hospital Medical Services at the new council's imbalance (14 May, p 1418) turn back to the actual results ( 7 May, p 1342).

In 13 regions in England 12 general practitioners were returned to council for 1988-90, but no fewer than seven of these were returned unopposed. Surely the senior hospital doctors should do something about that lamentable fact in 1990? Genera practitioners predominate numerically, but in those regions where a consultant did stand he made a respectable showing. The percentage of member voting was so low that a little energetic "whipping" could go far to remedy such reverses. The one certain way not to win a contest is to fail to enter and no amendment of the system can change that.

David Gullick

\section{Welwyn,}

Welwyn,
Herts AL6 0QH

\section{Funding and patient care in Scotland}

SIR,-I feel I must challenge Sir George Godber's original premise and the supporting statement made by Scrutator (21 May, p 1477) that much more of the tax payers' money is being spent on Scotland's health than is the case south of the border.

In a carefully researched paper Glen and Hulbert showed that the traditional method of making comparisons, by applying the Resource Allocation Working Party formula to the health budget of England, Scotland, Wales, and Northern Ireland, is flawed. ${ }^{1}$ They argued that conclusions based on this oversimple calculation are untenable.

One of the main factors, apart from Scotland's significantly higher standardised mortality ratio, is the geography of the country. The density of population is five times lower than in England, yet a health service still has to be provided in all regions and in the larger islands. Another important factor is that in England a substantially higher proportion of patients in the mental handicap and geriatric sectors are in the care of local authorities and private institutions.

We would not deny that we are slightly better funded. Nevertheless, the recent survey on health service provision initiated by the BMA's Scottish council has shown significant problems in some areas and any comparative reduction in our health budget can only have a serious effect on facilities and standards of patient care in Scotland.

BMA Scottish Office,

J A FORD

Edinburgh EH3 7QP

Glen ACA, Hulbert JKM. Hospital and community health costs:
England and Scotland compared. Br Med f 1987;295:707-10.

\section{Euthanasia}

SIR,-In the report of the recent council meeting (14 May, p 1408) I am quoted as saying during the euthanasia debate, "On occasions there would be no alternative but to take life." This is inaccurate. I was arguing against an amendment to a crucial paragraph in the conclusion of the working party's report. I quoted from the report saying, "In this paragraph the proposition that some might argue is that in certain hypothetical cases 'there appears to be no alternative but to take life' " and continued, "But this paragraph then proceeds quite rightly to refute this argument."

I can see no circumstances where a doctor is justified in actually killing a patient. We can and must relieve suffering in our patients, but this does not give us the right actually to kill them. I repeat my statement given in the debate that I consider the report to be a magnificent statement of ethics, a monument to the skill and compassion of the working party, and a report which reflects nothing but credit on the profession as a whole and the BMA in particular.

Peter HaWker

Stratford on Avon CV37 0JE

SIR,-Dr Roger Higgs (14 May, p 1348) discusses the report of the BMA working party on voluntary euthanasia. The original working party included at least one doctor who represented the sizable minority of doctors and sizable majority of patients who favour legalisation. The BMA would have had no difficulty in finding a replacement with similar views when other commitments made it impossible for me to continue to sit on the working party.

Had I remained, I could not have put my signature to the muddled and evasive report that has emerged. A dissenting view would have emphasised that the profession is far from united on this issue. Is the BMA so different from its Dutch counterpart that it can neither acknowledge nor accommodate this divergence?

The Voluntary Euthanasia Society,

JONATHAN MILLER

London W8

${ }_{*}^{* *}$ The Secretary writes: "Dr Miller was invited to be a member of the working party at the beginning of 1987 and accepted. Notice of the first meeting, on 15 April, was sent out in March, and we did not receive any indication that he would not attend. Only later, after extensive chasing of his secretary, did we discover that he would not be available until the end of the year.

"By then three meetings had taken place, and it was impossible to find a replacement for Dr Miller. The membership of the working party was established by council, whose next meeting was not until October. We did, however, take written and oral evidence from the Voluntary Euthanasia Society and other groups, including the Royal Dutch Medical Association. It is also important to note that the working party was studying 'euthanasia,' not 'voluntary euthanasia'-there is a difference."-ED, $B M \mathcal{H}$.

\section{Drug points}

\section{Toxic epidermal necrolysis and trimethoprim}

Messrs G Das, M J Bailey, and J E A Wickham (Institute of Urology, London WC2H 8JE) write: We support Dr C Nwokolo and others (2 April, p 970) in incriminating trimethoprim as a cause of toxic epidermal necrolysis. In August 1986 a woman was admitted to the London Stone Clinic for endoscopic 
extraction of a ureteric calculus. She was started on $200 \mathrm{mg}$ of trimethoprim twice daily in accordance with our policy of prophylaxis against urinary infection. She soon developed a cutaneous erythematous reaction, which progressed rapidly to florid toxic epidermal necrolysis. Although she had denied any allergies at the initial clerking it subsequently emerged that she did have a history of reaction to trimethoprim

We have treated over 2000 patients for urinary calculi at the London Stone Clinic. Most received trimethoprim, and this was the only case of epiderma necrolysis. In view of its widespread use doctors should be aware that trimethoprim is capable of causing toxic epidermal necrolysis.

\section{Idiosyncratic reaction resembling toxic epidermal necrolysis caused by chloroquine and Maloprim}

Mr P A PHILlIPS-HowARD (London School of Hygiene and Tropical Medicine, London WC1E 7HT) and Dr J WARWICK BUCKLER (City Hospital, Nottingham) write: Serious cutaneous reactions have been associated with the combination of pyrimethamine and sulfadoxine (Fansidar) used for malaria chemoprophylaxis. ${ }^{12}$ We report a rare and severe idiosyncratic cutaneous reaction to chloroquine and the combination of pyrimethamine and dapsone (Maloprim).

A 59 year old white British man visited the Republic of South Africa in May 1986. He started a prophylactic regimen of chloroquine $300 \mathrm{mg}$ (Nivaquine, May and Baker Ltd) weekly and pyrimethamine $12.5 \mathrm{mg}$ and dapsone $100 \mathrm{mg}$ (Maloprim, Wellcome Foundation Ltd) one tablet weekly, taking both on the same da five days before he set off. Concurrent drugs were 1 of aspirin and $40 \mathrm{mg}$ of propranolol daily. He had taken these continuously for the past decade with no untoward effect.

Within 24 hours of arrival he developed bullous erythema on exposed skin areas. Symptoms resem bling sunburn subsided over two to three days. A second dose of the same regimen was taken one week after the first. Within three to four hours he developed giant bullae affecting the soft palate, uvula, and epiglottis. A single oral dose of $5 \mathrm{mg}$ of dexamethasone was given to relieve oedematous swelling of his pharynx.

Some of the lesions ulcerated and the skin exfoliated on large areas of the limbs and trunk. Nikolsky's sign was positive: superficial layers of skin could be rubbed off with light pressure. There was severe lassitude and he felt feverish. The chemoprophylaxis was stopped after the second dose, but the skin changes took 10 days to resolve and left scars on the legs.

Inquiries to the drug companies found no simila reports, suggesting no association with batch impurities. The clinical manifestations closely resembled toxic epidermal necrolysis, ${ }^{3}$ although it was not possible to confirm the diagnosis by biopsy. No other cases attributed to prophylaxis with chloroquine and the combination of pyrimethamine and dapsone have been reported to the Committee on Safety of Medicines in Britain (personal communication).

The temporal association strongly implicates malaria chemoprophylaxis, but the evidence about which drug was the cause is incomplete. Patch testing was rejected because this would reflect only sensitisation to surface allergens, and prick testing was considered to be too dangerous. The patient had travelled extensively and had taken the combination of pyrimethamine and dapsone on at least 20 previous occasions without complication. This was, however, the first time he had taken chloroquine.

Serious cutaneous adverse reactions have been associated with dapsone, ${ }^{4}$ sulphonamides, ${ }^{5}$ and chloroquine ${ }^{6}$ at high doses. Severe skin reactions to prophylactic doses are extremely rare. Recently, a case of severe dapsone syndrome was attributed to the combination of pyrimethamine and dapsone taken once weekly in addition to chloroquine. ' Toxic epidermal necrolysis, with a positive Nikolsky's sign, has been reported during treatment with chloroquine alone. ${ }^{8}$

1 Miller KD, Lobel HO, Satriale RF, et al. Severe cutaneous reactions among American travellers using pyrimethamine- sulfadoxine (Fansidar) for malaria prophylaxis. Am $\mathcal{f}$ Trop Med Hyg 1986:35:451-8.

2 Hellgren U, Rombo L, Berg B, et al. Adverse reactions to sulphadoxine-pyrimethamine in Swedish travellers: implications for prophylaxis. Br Med f 1987;295:365-6.

3 Goldstein SM, Wintroub BW, Elias PM, et al. Toxic epiderma necrolysis. Arch Dermatol 1987;123:1153-5.

4 Browne SG. Toxic epidermal necrolysis. Br Med f 1961;i:550-3. Bergoend H, Loffler A, Amar R, Maleville J. Reactions cutanées survenues au cours de la prophylaxie de masse de la méningite cérébro-spinale par un sulfamide long-retard (à propos de 997 cas). Ann Dermatol Venereol 1968;95:481-90.

6 Biilmann-Petesen ML. Exfoliative erythroderma after chloroquine treatment. Ugeskr Laeger 1959;121:579-80.

Grayson ML, Yung AP, Doherty RR. Severe dapsone syndrome due to weekly Maloprim. Lancet 1988;i:531.

8 Kanwar AJ, Singh OP. A report of toxic epidermal necrolysis after the ingestion of one tablet of chloroquine Indian $\mathcal{J}$ Dermatol 1978;21:73-7.

\section{Acyclovir malabsorption}

Dr A Mindel and Ms O CARney (Academic Department of Genitourinary Medicine, University College and Middlesex School of Medicine, London W1N 8AA) write: Little is known about the exact site of absorption of oral acyclovir, although it is presumed to be absorbed over the entire length of the smal intestine. We recently saw a patient with recurren genital herpes whose terminal ileum had been removed at surgery. She failed to respond to suppressive ora acyclovir in a dose up to $400 \mathrm{mg}$ four times a day and was found to have malabsorption of the drug. Adequate therapeutic concentrations were obtained and the recurrences suppressed when the dose was increased to $800 \mathrm{mg}$ four times a day.

A 22 year old woman presented in December 1986 with a history of recurrent genital herpes. Her attack occurred every five to six weeks and each lasted five to 10 days. These had been occurring since mid-1985. In 1979 her appendix had been removed after several months of abdominal pain. In 1980 she presented with acute abdominal pain and was found to have smal bowel obstruction due to adhesions. At surgery $0.6 \mathrm{~m}$ of terminal ileum was removed, although the ileocaecal valve was preserved. After strgery she complained of intermittent diarrhoea. In 1986 she had extensive gastrointestinal investigations. Her weight was constant and there was no evidence of malabsorption; albumin, folate, and vitamin $\mathbf{B}_{12}$ concentrations were normal. In February 1987 she was given suppressiv oral acyclovir for recurrent genital herpes at a dose of $200 \mathrm{mg}$ four times daily, but her recurrences continue with unchanged frequency and severity. In June the dose was increased to $400 \mathrm{mg}$ four times daily, with little success. Her plasma acyclovir concentration was measured two hours after the last oral dose and found to be $0.32 \mu \mathrm{mol} / \mathrm{l}$ (normal 5.21 (SD 1.32) $\mu \mathrm{mol} / \mathrm{l}$ table) (P D Whiteman et al, second internationa acyclovir symposium, 1983). We therefore increased the dose to $800 \mathrm{mg}$ four times a day. At this dose the peak serum value was $3.34 \mu \mathrm{mol} / 1$ (normal $8 \cdot 16(1.98)$ $\mu \mathrm{mol} / \mathrm{l}){ }^{1}$ From August to December she had no recurrences and we reduced her dose to $800 \mathrm{mg}$ twice daily; a few days later she had a breakthrough recurrence. She immediately returned to the highe dose and was subsequently free of recurrence.

Maximum plasma acyclovir values ( $\mu$ mol/l) taken two hours after last dose

\begin{tabular}{ccc}
\hline Dose $(\mathrm{mg})$ & Our patient & Experimental $^{\star}$ \\
\hline $200 \mathrm{mg}$ & Not measured & $3.02(0.50)$ \\
$400 \mathrm{mg}$ & 0.32 & $5 \cdot 21(1.32)$ \\
$800 \mathrm{mg}$ & 3.34 & $8 \cdot 16(1.98)$
\end{tabular}

${ }^{\star}$ Mean (SD) (P D Whiteman et al, second international acyclovir symposium, 1983).

Frequently occurring genital herpes may be controlled with suppressive oral acyclovir. ${ }^{1-3}$ On $200 \mathrm{mg}$ four times a day recurrences are rare and the few that occur will be minor and short lived. ${ }^{1}$ If a patient fails to respond to treatment there are several explanations to be considered. Is the medication being taken; are the recurrences herpes or some other genital complaintfor example, candida; could the patient have a drug resistant strain (already reported in immunocompromised patients $)^{4}$; and is the drug being absorbed? The possibility of poor absorption should be borne in mind particularly if the patient has had abdominal surgery. Our patient had no other obvious evidence of malabsorption. This suggests that acyclovir may be absorbed over only a very limited region of the bowel and that the problem may be overcome by increasing the total daily dose.

We thank Dr Lancaster-Smith from the Sloane Hospital in Kent for permission to report this case and Dr Holdich from the Wellcome Research Laboratories radioimmunoassay section, Beckenham, Kent, for measuring the serum acyclovir concentrations.

Douglas JM, Critchlow C, Benedetti J, et al. A double-blind study of oral acyclovir for suppression of recurrences of genital herpes simplex virus infection. $N$ Engl f Med 1984:310: 1551-6.

2 Mindel A, Weller IVD, Faherty A, et al. Prophylactic oral acyclovir in recurrent genital herpes. Lancet 1984;ii:57-9.

Straus SE, Takiff HE, Seidlin M, et al. Suppression of frequently recurring genital herpes. A placebo-controlled double blind trial of oral acyclovir. N Engl f Med 1984;310:1545-50.

Burns WH, Saral R, Santos GW, et al. Isolation and characterisation of resistant herpes simplex virus after acyclovir therapy. Lancet 1982;i:421-3.

\section{Sterile abscess formation by continuous} subcutaneous infusion of diamorphine

Drs P J HoskIN and G W HANKS and Sister I D WHITE (Continuing Care Unit, Royal Marsden Hospital, Sutton, Surrey SM2 5PT) write: Continuous sub cutaneous infusion of diamorphine and antiemetic drugs in patients with advanced cancer is generally free from complications apart from minor induration and erythema at the skin site. ${ }^{1}$ We have observed a severe local reaction with sterile abscess formation a the site of infusion in two patients who received a subcutaneous infusion using a Graseby MS series syringe driver and a 25 gauge Vygon butterfly infusion set.

A 70 year old woman received aqueous diamorphine over 22 days in a dose increasing from 30 to $100 \mathrm{mg} / \mathrm{h}$ Solutions of 60 to $222.5 \mathrm{mg} / \mathrm{ml}$ were infused at rates of 0.3 to $0.5 \mathrm{ml} / \mathrm{h}$. Frequent changes of site were required (mean every 2.5 days, range 20 hours to 5 days) because of a severe reaction consisting of extensive induration and fluctuant swelling at the injection site. The site of infusion, concentration of diamorphine, and volume of infusate did not influence this reaction; nor did the addition of chlorpromazine or methotrimeprazine. Biopsy specimens taken from each of nine sites about 16 hours after death showed histological appearances typical of a sterile abscess. Swabs from fluid drained from each site grew only normal skin flora.

A 42 year old woman received aqueous diamorphine increasing from 83.3 to $200 \mathrm{mg} / \mathrm{h}$. Solutions of 125 to $240 \mathrm{mg} / \mathrm{ml}$ were delivered at rates of 0.6 to $0.8 \mathrm{ml} / \mathrm{h}$ Within 24 hours the infusion site became painful with erythema, induration, and a fluctuant mass. The site was changed to the opposite thigh, where a similar reaction developed. Fluid obtained from surgical drainage of the abscesses grew only normal skin flora.

The development of sterile abscesses after subcutaneous injection has been reported previously with chlorpromazine ${ }^{2}$ (M Lacomme, May and Baker abstract No 54107,1953$)$. In the cases reported here simple aqueous solutions of diamorphine hydrochloride without preservative were used, and the addition of phenothiazines in the first case did not affect the reaction. The only common feature was the use of relatively high doses of diamorphine. This has previously been associated with increased local skin irritation $^{12}$ but not with abscess formation. The infusion system is commonly used and has not been associated with specific reactions. This idiosyncratic response to subcutaneous infusion of aqueous diamorphine is unusual. Early recognition of such complications and use, whenever possible, of the recta route as the first alternative to oral treatment are recommended.

We thank Dr R L Carter for performing the histological examination.

Nicholson $\mathrm{H}$. The success of the syringe driver. Nursing Times 1986;82:49-51.

Regnard C, Newbury A. Pain and the portable syringe pump.

Nursing Times 1983;79:25-8. 